\title{
Comparison of 3D scanned kidney stone model versus computer-generated models from medical images
}

\author{
Galeta, T. ${ }^{a}$, Pakši, I. ${ }^{a}$, Šišić, D. ${ }^{a}$, Knežević, $M .{ }^{b}$ \\ aJ.J. Strossmayer University of Osijek, Mechanical Engineering Faculty in Slavonski Brod, Croatia \\ 'Department of Urology, General Hospital “Dr. Josip Bencevic”, Slavonski Brod, Croatia
}

\section{A B S T R A C T}

With a goal to evaluate accuracy of kidney stone models created from medical images, comparison of computer-generated models against 3D scanned model is performed. Computer-generated models are made using 6 free and one commercial software for medical images obtained by computed tomography (CT) with a slice thickness of $5 \mathrm{~mm}$. Digitized volume of the same kidney stone was obtained after its surgical removal and digitized using a contactless 3D scanner ATOS Compact Scan. Due to the complexity of kidney stone, the scanned reference model is not completely identical to real surgically removed stone from a patient. High maximum deviation is positioned mainly in the areas where the actual kidney stone is not scanned. The average surface deviation is in the range of $0.24354 \mathrm{~mm}$ to $0.44719 \mathrm{~mm}$. Results reveals that the accuracy of the computer-generated models depends on quality of algorithms for tissue segmentation implemented in a particular software and on the skill of user. All software enabled us to create a 3D model of the kidney with clearly visible position of a kidney stone inside, accurate enough for planning the operation. It is possible to get a higher model accuracy by reducing the slice thickness during medical imaging; however, it increases the dose of radiation. Therefore, it is necessary to individually determine the optimum balance between the required quality of images and the amount of radiation that the patient is exposed to during recording.
\end{abstract}

\section{ARTICLE INFO}

Keywords:

Kidney stone

Medical images

3D scanning

Computer tomography (CT)

3D model

Accuracy

*Corresponding author:

tgaleta@sfsb.hr

(Galeta, T.)

Article history:

Received 23 February 2017

Revised 3 July 2017

Accepted 5 July 2017

\section{References}

[1] Rengier, F., Mehndiratta, A., von Tengg-Kobligk, H., Zechmann, C.M., Unterhinninghofen, R., Kauczor, H.-U., Giesel, F.L. (2010). 3D printing based on imaging data: Review of medical applications, International Journal of Computer Assisted Radiology and Surgery, Vol. 5, No. 4, 335-341, doi: 10.1007/s11548-010-0476-X.

[2] Ruggeri, M., Tsechpenakis, G., Jiao, S., Jockovich, M.E., Cebulla, C., Hernandez, E., Murray, T.G., Puliafito, C.A. (2009). Retinal tumor imaging and volume quantification in mouse model using spectral-domain optical coherence tomography, Optics Express, Vol. 17, No. 5, 4074-4083, doi: 10.1364/0E.17.004074

[3] Robiony, M., Salvo, I., Costa, F., Zerman, N., Bazzocchi, M., Toso, F., Bandera, C., Filippi, S., Felice, M., Politi, M. (2007). Virtual reality surgical planning for maxillofacial distraction osteogenesis: The role of reverse engineering rapid prototyping and cooperative work, Journal of Oral and Maxillofacial Surgery, Vol. 65, No. 6, 1198-1208, doi: $10.1016 /$ i.joms.2005.12.080.

[4] Chougule, V.N., Mulay, A.V., Ahuja, B.B. (2014). Development of patient specific implants for Minimum Invasive Spine Surgeries (MISS) from non-invasive imaging techniques by reverse engineering and additive manufacturing techniques, Procedia Engineering, Vol. 97, 212-219, doi: 10.1016/i.proeng.2014.12.244.

[5] Shim, M.-B., Gunay, M., Shimada, K. (2009). Three-dimensional shape reconstruction of abdominal aortic aneurysm, Computer-Aided Design, Vol. 41, No. 8, 555-565, doi: 10.1016/j.cad.2007.10.006. 
[6] Thali, M.J., Braun, M., Dirnhofer, R. (2003). Optical 3D surface digitizing in forensic medicine: 3D documentation of skin and bone injuries, Forensic Science International, Vol. 137, No. 2-3, 203-208, doi: 10.1016/i.forsciint. 2003.07.009.

[7] ATOS Compact Scan - GOM, from http://www.gom.com/metrology-systems/system-overview/atos-compactscan.html, accessed September 8, 2015.

[8] Barbero, B.R., Ureta, E.S. (2011). Comparative study of different digitization techniques and their accuracy, Computer-Aided Design, Vol. 43, No. 2, 188-206, doi: 10.1016/i.cad.2010.11.005.

[9] Tóth, T., Živčák, J. (2014). A comparison of the outputs of 3D scanners, Procedia Engineering, Vol. 69, 393-401, doi: 10.1016/i.proeng.2014.03.004.

[10] Gapinski, B., Wieczorowski, M., Marciniak-Podsadna, L., Dybala, B., Ziolkowski, G. (2014). Comparison of different method of measurement geometry using CMM, optical scanner and computed tomography 3D, Procedia Engineering, Vol. 69, 255-262, doi: 10.1016/i.proeng.2014.02.230.

[11] Brisbane, W., Bailey, M.R., Sorensen, M.D. (2016). An overview of kidney stone imaging techniques, Nature Reviews Urology, Vol. 13, 654-662, doi: 10.1038/nrurol.2016.154.

[12] Budzik, G., Burek, J., Bazan, A., Turek, P. (2016). Analysis of the accuracy of reconstructed two teeth models manufactured using the 3DP and FDM technologies, Strojniški vestnik - Journal of Mechanical Engineering, Vol. 62, No. 1, 11-20, doi: 10.5545/sv-jme.2015.2699.

[13] Mandić, M., Galeta, T., Raos, P., Jugović, V. (2016). Dimensional accuracy of camera casing models 3D printed on Mcor IRIS: A case study, Advances in Production Engineering \& Management, Vol. 11, No. 4, 324-332, doi: 10.14743/apem2016.4.230. 


\title{
Primerjava 3D skeniranega modela ledvičnega kamna z računalniško generiranimi modeli medicinskih slik
}

\author{
Galeta, T. ${ }^{a}$, Pakši, I. ${ }^{a}$, Šišić, D. ${ }^{a}$, Knežević, M. ${ }^{b}$ \\ aJJ. Strossmayer University of Osijek, Mechanical Engineering Faculty in Slavonski Brod, Croatia \\ 'Department of Urology, General Hospital "Dr. Josip Bencevic", Slavonski Brod, Croatia
}

\section{POVZETEK}

S ciljem oceniti natančnost modelov ledvičnih kamnov, ustvarjenih iz medicinskih slik, je narejena primerjava računalniško generiranih modelov in 3Dskenirannih modelov. Računalniško generirani modeli so bili izdelani z uporabo šestih brezplačnih in ene komercialne programske opreme za medicinske slike, pridobljene $\mathrm{z}$ računalniško tomografijo (CT) $\mathrm{z}$ debelino rezin $5 \mathrm{~mm}$. Digitalizirana prostornina enakega ledvičnega kamna je bila pridobljena po kirurški odstranitvi in digitalizaciji z brezkontaktnim 3D skenerjem ATOS Compact Scan. Zaradi kompleksnosti ledvičnega kamna, skenirani referenčni model ni popolnoma enak pravemu, pacientu kirurško odstranjenemu kamnu. Največja odstopanja so prisotna predvsem na območjih, kjer se dejanski ledvični kamen ne skenira. Povprečno odstopanje površine je v območju od $0,24354 \mathrm{~mm}$ do $0,44719 \mathrm{~mm}$. Rezultati kažejo, da je natančnost računalniško generiranih modelov odvisna od kakovosti algoritmov za segmentacijo tkiv, ki so vključeni v določeni programski opremi in od znanja uporabnika. Vsaka programska oprema je omogočila izdelavo 3D modela ledvice, $z$ jasno vidnim položajem notranjega ledvičnega kamna, ki je bil dovolj natančen za načrtovanje operacije. Večjo natančnost modela je mogoče doseči s stanjšanjem debeline rezine med medicinskim slikanjem, vendar je ob tem treba povečati odmerek sevanja. Zato je treba individualno določiti optimalno ravnotežje med zahtevano kakovostjo slik in količino sevanja, ki ji je izpostavljen bolnik med snemanjem.

\section{PODATKI O ČLANKU}

Ključne besede:

Ledvični kamen

Medicinske slike

3D skeniranje

Računalniška tomografija (CT)

3D model

Natančnost

*Kontaktna oseba:

tgaleta@sfsb.hr

(Galeta, T.)

Zgodovina članka:

Prejet 23. februarja 2017

Popravljen 3. julija 2017

Sprejet 5. julija 2017 